\title{
A Promising Physical Pest-Control System Demonstrated in a Greenhouse Equipped With Simple Electrostatic Devices That Excluded All Insect Pests: A Review
}

\author{
Yoshihiro Takikawa ${ }^{1}$, Koji Kakutani ${ }^{2,3}$, Yoshinori Matsuda ${ }^{4}$, Teruo Nonomura ${ }^{4}$, Shin-ichi Kusakari ${ }^{5}$ \\ \& Hideyoshi Toyoda ${ }^{5}$ \\ ${ }^{1}$ Plant Center, Institute of Advanced Technology, Kindai University, Wakayama, Japan \\ ${ }^{2}$ Pharmaceutical Research and Technology Institute, Kindai University, Osaka, Japan \\ ${ }^{3}$ Anti-Aging Centers, Kindai University, Osaka, Japan \\ ${ }^{4}$ Laboratory of Phytoprotection Science and Technology, Faculty of Agriculture, Kindai University, Nara, Japan \\ ${ }^{5}$ Research Association of Electric Field Screen Supporters, Nara, Japan \\ Correspondence: Koji Kakutani, Pharmaceutical Research and Technology Institute, Kindai University, Osaka \\ 577-8502, Japan. Tel: 81-06-6721-2332. E-mail: kakutani@kindai.ac.jp
}

Received: August 7, 2019

Accepted: September 15, 2019

Online Published: November 15, 2019

doi:10.5539/jas.v11n18p1

URL: https://doi.org/10.5539/jas.v11n18p1

\begin{abstract}
Applied electrostatic engineering can be used to construct greenhouses that prevent entry of insect pests. Two types of electric field screen were used to exclude pests from the greenhouse: single- and double-charged dipolar electric field screens (S- and D-screen, respectively). The S-screen consisted of iron insulated conductor wires (ICWs) arrayed in parallel (ICW-layer), a grounded metal net on either side of the ICW-layer, and a direct current voltage generator. S-screens were attached to the side windows of the greenhouse to repel whiteflies (Bemisia tabaci) that approached the nets. The D-screen was installed in a small anteroom at the greenhouse entrance to capture whiteflies entering through it. The ICW-layers of the D-screen were oppositely charged with equal voltages and arrayed alternately, and an insulator board or grounded metal net was placed on one side of the ICW-layer. The ICW-layers captured whiteflies entering the electric field of the double-charged dipolar electric field. Three screens equipped with yellow or gray boards or a grounded metal net were installed in the anteroom based on the airflow inside the room, as most whiteflies were brought in by air when the door was opened. Two D-screens with boards were useful for directing the airflow toward the wall with the netted D-screen. This screen eliminated the insects and the pest-free air was circulated inside the greenhouse. The D-screen with the yellow board attracted the whiteflies and was effective for trapping them when there was no wind. Our method kept the greenhouse pest-free throughout the entire period of tomato (Solanum lycopersicum) cultivation.
\end{abstract}

Keywords: electric field screen, pest management, photo-selective nets, whiteflies

\section{Introduction}

The protection of crop plants from infection or attack by pathogens and pests using safe, environmentally benign methods has been a long-standing goal. Much effort has focused on developing biological and chemical methods to achieve this, including the production of resistant crop plants using conventional and new biotechnological techniques, biocontrol of pathogens and pests using antibacterial, antifungal, and entomopathogenic microorganisms, and the screening of biologically synthesized compounds that inhibit pathogen growth (Toyoda et al., 2015a, 2000). Despite much interesting work, there has been little practical progress because the protective effects are easily overcome, and because of problems with agent preparation, limited targets for application, and high costs (Toyoda et al., 2015a). The principal barrier to practical implementation lies in the application of individual methods for pathogen and pest control at scales larger than in test experiments, and variable environmental conditions. Trials have shown that the aforementioned techniques are, in essence, supplementary measures suitable for a limited range of targets under specific conditions. The lack of reliable basic methods that can be combined to constitute a suitable approach must be addressed. 
Once a realistic research objective is set, steady progress can be made via the creation and refutation of working hypotheses formulated from reproducible experimental results, eventually leading to new applications for electric field screens (Toyoda \& Matsuda, 2015b). An electric field screen is an air-shielding apparatus based on the principles of applied electrostatic engineering, and was introduced in 2006 as a physical tool to trap airborne conidia of tomato powdery mildew (Oidium neolycopersici) (Matsuda et al., 2006). Powdery mildews are fungal pathogens in the order Erysiphales that affect many plant species. Powdery mildews grow well in environments with high humidity and moderate temperatures; greenhouses provide an ideal moist and temperate environment for spreading these diseases. We focused on O. neolycopersici on greenhouse tomatoes (Solanum lycopersicum (Solanaceae)), which infects not only all commercial tomato cultivars tested (Kiss et al., 2001), but also cultivars bred for resistance against a European isolate of the tomato powdery mildew pathogen (Kashimoto et al., 2003). In a preliminary survey, we found fungicide-tolerant isolates of $O$. neolycopersici on naturally infected tomato leaves, indicating the need for alternative measures to control the pathogen. Although breeding pathogen-resistant traits is the conventional method used to protect crop plants from disease (Lindhout et al., 1994; Mieslerová et al., 2000; van der Beek et al., 1994), we need to remain alert to outbreaks of new pathogenic strains of the pathogen on resistant tomatoes (Brown, 2002; Lebeda \& Mieslerová, 2002; Matsuda et al., 2005). Therefore, we developed new physical electrostatics-based control measures to prevent the spread of the disease (Matsuda et al., 2006; Nonomura et al., 2008; Kakutani et al., 2012a; Takikawa et al., 2016).

Initially, the test apparatus was conceived as a new device for capturing airborne spores of phytopathogenic fungi during crop cultivation in greenhouses (Shimizu et al., 2007). Physical methods, especially those exploiting electrostatic phenomena, can generate physical forces sufficiently strong to catch airborne fungal spores (Takikawa et al., 2014) or small flying insects that may pass through the conventional insect netting used to protect greenhouse crops (Kakutani et al., 2012a, 2017; Takikawa et al., 2016, 2019; Tanaka et al., 2008; Nonomura et al., 2012, 2014a). If an effective force could be generated, an electrostatic approach would be an extremely promising tool to provide a spore-free, pest-free space for crop plants in greenhouse environments (Figure 1A).

A

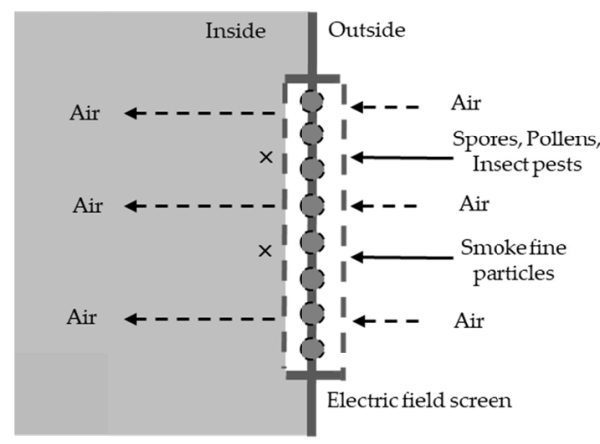

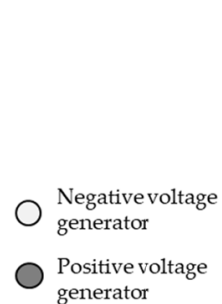

B

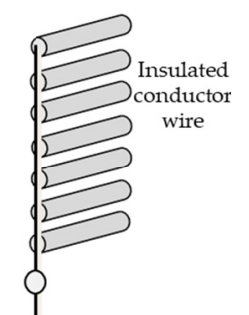

Electrostatic field

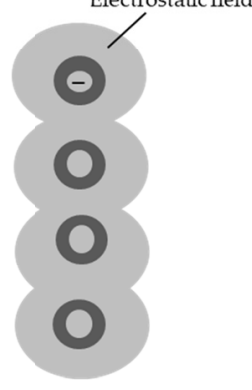

Single-charged monopolar type
C

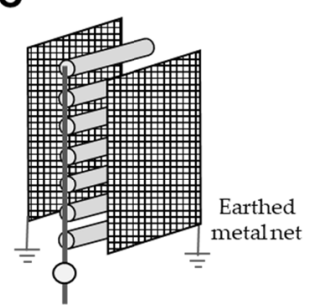

D


Single-charged dipolar type
Double-charged dipolar type

Figure 1. Conceptual diagram of the roles of the electric field screen (A), schematic representations of single-charged monopolar (B), single-charged dipolar (C), and double-charged dipolar electric field screens (D) and a cross-sectional view of the insulated conductor wires (ICWs) with an electrostatic field or static electric field in each screen

As the research progressed, the structure of the electric field screen was optimized so that it could capture not only fungal spores and flying insect pests, but also pollen grains (Takikawa et al., 2017a) that cause pollinosis (Kaneko et al., 2005; Matsuda \& Toyoda, 2018a), and fine particles (Takikawa et al., 2017b; Matsuda et al., 
2018b) in tobacco smoke that can cause disease, disability, and death (Schlesinger et al., 2007; Cao et al., 2015; Saulyte et al., 2014). Advances in electric field screen technology have allowed broader application of the device, from agricultural fields, e.g., crop production, processing, and storage, to environmental and public health. Indeed, electric field screens can be used in houses, hospitals, schools, greenhouses (for crop production), warehouses, plants (for processing harvested crops), and animal husbandry facilities (Toyoda \& Matsuda, 2015b) A wide variety of electric field screen structures can be customized to prevent the entry of biotic and abiotic environmental nuisances (Matsuda \& Toyoda, 2018a). Figures 1B-1D show the electric field screen types used herein. The terms 'single-charged' and 'double-charged' in the figure refer to how the voltage is applied, i.e., using either a single negative or positive voltage generator, or both types of voltage generator, to produce monopolar and dipolar electric fields, respectively (Jones \& Childers, 2002; Griffith, 2004; Giancoli, 2005; Halliday et al., 2005). The rod-shaped structures in the figures represent metal (iron or copper) wire with an insulating coating, i.e., an insulated conducting wire; the different colors indicate the application of a positive or negative voltage. The net-like structure is a grounded metal net made of stainless steel or iron. All of the screens have a simple, common structure; therefore, the cost of production is relatively low. Using these devices, we describe the development of two types of electric field screen, with unique structures and electrostatic mechanisms, to construct an ideal greenhouse that can completely prevent the entry of greenhouse pests.

\section{Structure and Function of a Double-Charged Dipolar Electric Field Screen (D-Screen)}

\subsection{Basic Structure}

There are various types of electric field screen, all of which include a screen body and an electric driver, i.e., an electric power source and direct current (DC) voltage generator. While the same electric driver is used for all electric field screen types, the screen body may vary depending on the application, and all types involve insulated conductor wires (ICWs) that are arranged vertically to make a barrier of static electric fields (Figure 1C and D). An insulated conductor is produced by passing a copper or iron wire through a soft polyvinyl chloride (PVC) tube (1-mm thickness, $1 \times 10^{9} \Omega \cdot \mathrm{m}$ ) (Tanaka et al., 2008).

The voltage generator can be operated by a 12 -volt storage battery, and used to boost the initial voltage $(12 \mathrm{~V})$ to the designated voltage (1-30 kV) using a transformer and Cockcroft circuit (Wegner, 2002) integrated into an electric circuit in the voltage generator (Supplementary Figures 1A and 1B). The difference between the negative and positive voltage generators is that the Cockcroft circuit is set in reverse, such that the negative charge (or free electrons) moves in the reverse direction. A negative voltage generator draws negative free electrons from the ground, which serves as an infinite source or sink of electrons (a source in this case) and supplies electrons to the conducting wire (Jonassen, 2002). A negative charge accumulates on the surface of the wire conductor and is induced on the outer surface of the insulated coating of the wire, thereby negatively electrifying the insulator via dielectric polarization (Jones \& Childers, 2002; Griffith, 2004) (Supplementary Figure 1A, see Appendix A). A positive voltage generator pushes free electrons to the ground (an infinite sink of electrons) to positively charge the conductor wire (positive electrification) (Jonassen, 2002), and a positive charge is induced on the outer surface of the insulating coating surrounding the conducting wire (positive electrification) due to electrostatic induction (Griffith, 2004). The positive electrification of the insulated conducting wire causes the insulating coating to become positively charged as a result of dielectric polarization (Supplementary Figure 1B, see Appendix A).

The most advantageous characteristic of the voltage generator used in this study is the ability to operate the generator using a $12-\mathrm{V}$ DC source. The electric power consumption is small $(5 \mathrm{~W})$, effectively equivalent to that of a small lightbulb, so the screen can operate for long periods using a standard storage battery. This feature is useful for the practical implementation of electric field screens. Here, two types of electric field screen are used for this purpose: a single-charged dipolar electric field screen (S-screen; with grounded metal nets) (Figure 1C) and a D-screen (single layer type) (Figure 1D).

\subsection{A Non-grounded Electric Circuit is Essential for Practical Implementation}

In the standard electric circuit configuration for negative voltage charging of the electric field screen, electrons are pumped from the ground and supplied to the ICW using a voltage generator. The grounded metal net eventually becomes electrified by electrostatic induction (Griffith, 2004). In terms of current movement, the same amount of electricity can be supplied by the ground to create a static electric field (Supplementary Figure 1C, see Appendix A). In a non-grounded circuit, the free electrons in the metal net are supplied directly to the ICW using the voltage produced by the generator (Supplementary Figure 1D, see Appendix A). Therefore, the electric field screen with this circuit does not need to be grounded. By this principle, the electric field screen can be placed freely, allowing portable electric field screens (Takikawa et al., 2015a, 2017c). The principle is exactly 
the same in the double-charged type, which uses both negative and positive voltage generators; namely, the free electrons in the metal net are supplied to the ICW (Supplementary Figure 1E, see Appendix A) (Matsuda et al., 2015a). In this case, however, the potential difference between the opposite poles (oppositely charged ICWs) doubles, and the force generated is strengthened (Matsuda \& Toyoda, 2018a).

\subsection{Insect-Capturing Function of a Double-Charged Dipolar Electric Field Screen}

The whitefly (Bemisia tabaci Gennadius (Hemiptera: Aleyrodidae)) is a major pest in tomato cultivation capable of passing through conventional insect-proof nets (approximately $1.5 \mathrm{~mm}$ mesh) (Perring, 2001). The greatest economic threat in tomato cultivation is the transmission of damaging plant viruses, primarily Geminiviruses (Cohen \& Berlinger, 1986; Oliveira et al., 2001). The whitefly is difficult to control with insecticides because it feeds and oviposits mainly on the abaxial leaf surfaces (Sharaf, 1986), and because it has developed resistance to most classes of insecticides used for its control (Prabhaker et al., 1985; Palumbo et al., 2001; Horowitz et al., 2004; Nauen \& Denholm, 2005). Physical methods could provide an alternative means of managing this pest, since they would be compatible with other components of integrated pest management, have little impact on the environment, and reduce pesticide use, thus slowing the development of insecticide resistance (Weintrub \& Berlinger, 2004). In Japan, B. tabaci carries Tomato yellow leaf curl virus (TYLCV), which is a major cause of loss of tomato crops grown in greenhouses (Ueda \& Brow, 2006). To solve this problem, we used an electrostatic spore precipitator that had been developed to control tomato powdery mildew (Matsuda et al., 2006). This device is so effective at attracting air-borne conidia that tomato plants guarded by the spore precipitator remain uninfected (Matsuda et al., 2006). Despite the success of an electric field in pathogen control, a preliminary attempt to utilize this device for pest control was unsuccessful, because the electrostatic force of the spore precipitator was insufficient to retain trapped adult whiteflies. Successful application of the electric field screen enabled the management of whiteflies and other greenhouse pests (Kakutani et al., 2012a; Takikawa et al., 2016; Nonomura et al., 2012; Kakutani et al., 2017).

A double-charged dipolar-type screen is easily constructed by linking the ICWs alternately to negative and positive voltage generators (Nonomura et al., 2014a; Matsuda et al., 2012), forming an electric field between the oppositely charged conductor wires. We know that some electrons are present in air. In this field, the force always works to push electrons (negative electricity) toward the ground (Matsuda et al., 2012). In this field, however, the electrons accumulate around the positive pole because it is insulated (Figure 2A). When an insect enters this field, it can be captured in two ways (Matsuda et al., 2012). First, an insect enters the space near the negatively charged ICW (negative pole) (Figure 2B). Here, the insect is deprived of its free electrons and is electrified positively and attracted to the negative pole (discharge-mediated positive electrification). Alternatively, an insect enters the space near the positively charged pole (Figure 2C), receives electrons and is negatively electrified and attracted to the pole (charge-mediated negative electrification). Video data demonstrated the successful attraction of insects to the ICW (Video Supplement 1); the force was strong enough to capture the insects despite a $7 \mathrm{~m} / \mathrm{s}$ wind. Four kinds of greenhouse pests were included in the tests: whitefly (B. tabaci), western flower thrip (Frankliniella occidentalis Pergande (Thysanoptera: Thripidae)), green peach aphid (Myzus persicae Sulzer (Homoptera: Aphididae)), and tomato leaf-minor fly (Liriomyza sativae Blanchard (Diptera: Agromyzidae)). All of these pests can pass through conventional insect-proof nets (mesh size, $\sim 1.5 \mathrm{~mm}$ ) (Weintrub \& Berlinger, 2004). In farms, small insect pests pose a serious threat to crops. Three of the pests listed above cause particularly severe viral diseases, in addition to damage by pest attack. Whitefly, western flower thrips, and green peach aphid also carry the TYLCV, tomato spotted wilt tospovirus (TSWV), and cucumber mosaic virus (CMV), respectively. All of these pests have already acquired resistance against the major available insecticides (Nauen \& Denholm, 2005). Supplementary Table 1 (see Appendix B) shows that it is necessary to enhance the voltage in response to the wind velocity and size of the test insects; charging at $2.0 \mathrm{kV}$ was sufficient to capture all of the test insects at the highest wind speed with all screens. Because each screen was charged with the same magnitude of negative and positive voltages, the actual potential difference was twice that of the voltages listed in the table (Griffith, 2004). These results indicated that the screen could deal with all of the major pest insects tested under real-world conditions in a greenhouse. 
A

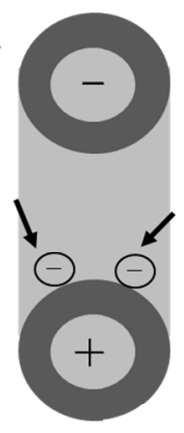

B

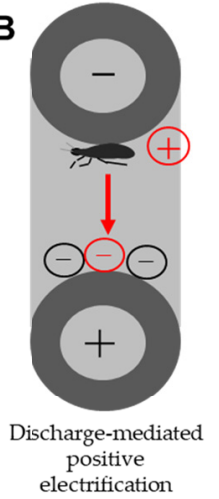

C

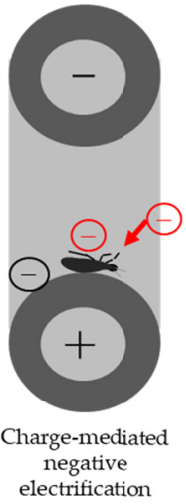

D

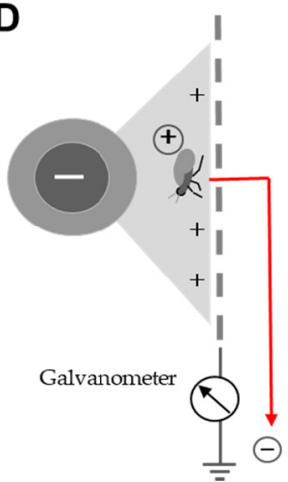

E

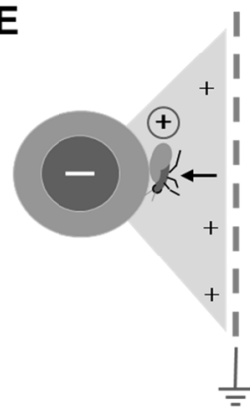

Figure 2. Schematic representation of the insect-capturing mechanism of the electric field of double-charged

(A-C) and single-charged (D, E) dipolar electric field screens

\subsection{Insect-Repelling Function of a Single-Charged Dipolar Electric Field Screen}

During our research, we devised a new method to generate a dipolar static electric field via single charging (Figure 1C). The electric field screen creating this field exhibited a revolutionary function for repelling insect pests (Nonomura et al., 2012; Matsuda et al., 2011, 2015b). An ICW charged with a negative voltage causes dielectric polarization within the insulating coating, creating a negatively charged insulator surface. The charged surface of the insulator produces an electrostatic field in the surrounding space (Griffith, 2004; Giancoli, 2005) (Figure 1B). The difference from the S-screen design is that we placed a grounded metal net inside the electrostatic field produced by the insulated conducting wire (Figure 1C) (Matsuda et al., 2011). The grounded metal net facing the charged insulated conductor becomes positively charged as a result of electrostatic induction (Griffith, 2004). Therefore, given that the ground is an electron source or sink, the free electrons in the metal net are pushed to ground by the negative insulator surface, because like charges repel. The electron deficiency in the metal net leaves the net with a positive charge. The opposite negative charge of the ICW and positively charged grounded net create a dipole, forming an electric field in the space between them. Therefore, we can create a positive pole (grounded metal net) without using a positive voltage generator. This is our single-charged dipolar electrification system. As shown in the figure, a static electric field is formed inside the electrostatic field. If we place another grounded net on the opposite side of the ICW, a static electric field forms in a manner consistent with bilateral symmetry. Accordingly, if we arrange the ICWs such that the upper and lower ends of the two static electric fields contact each other, a new electrostatic barrier consisting of static electric fields is formed (Figure 1C) (Matsuda et al., 2011).

In an experiment to examine the entry of insect pests, using partitions a greenhouse was divided into three rooms equipped with S-screens installed in the windows of both end rooms. The numbers of pests that entered each room were determined by counting the pests trapped on the yellow and blue adhesive plates hung therein. In this experiment, many whiteflies and tomato leaf-minor flies were trapped by the yellow plates. The results clearly show that the electric field screen excluded pests from the greenhouse. Over the 2-week experiment, an average of 1,000 pests entered the unguarded center room. In comparison, no pests were observed on the adhesive plates in screen-installed, door-locked rooms. In the side room that allowed the entry/exit of workers during the experiment, a few pests entered via the door. Nevertheless, the rate of pest exclusion exceeded $92 \%$, indicating 
that the electric field screens successfully prevented pest entry through the windows. Because numerous pests invaded the central room, it is reasonable to assume that similar numbers of pests attempted to invade both side rooms of the same greenhouse. Therefore, we initially expected to find that the electric field screens of these side rooms had trapped the same number of pests as were trapped in the central room. In fact, fewer insects were trapped, suggesting that the electric field screens actually repel the pests.

To prove this, an acrylic cylinder with an axial fan was constructed to examine the behavior of pests placed therein (Video Supplement 2) (Nonomura et al., 2012). The cylinder was placed in contact with the grounded metal net of the screen to observe the insects reaching the net. Moreover, insects were blown forward when they reached the net. With no airflow, all of the pests that reached the net stopped and placed their antennae or legs inside the static electric field of the screen, similar to a 'searching' behavior. These pests were deterred from entering the static electric field of the screen (Video Supplement 2A). In comparison, when the pests were blown forward, almost all of them clung to the net and assumed a posture to avoid the wind. However, some of the pests lost their grip and were forcibly pushed inside the screen. These pests were captured by the strong force of the electric field (Video Supplement 2B). These results are important as they confirm that all pests reaching the grounded net of the electric field screen attempted to avoid the field (i.e., they were repelled by the screen), and had to be forcibly pushed inside it by air. This is in good agreement with the experimental results described in the previous section. The results of the insect avoidance assay indicated that all insects tested exhibited avoidance behavior with respect to the static electric field. The insects tested covered 17 orders, 42 families, 45 genera, and 82 species (Supplementary Table 2, see Appendix B) (Matsuda et al., 2015b). From these results, we concluded that all insects are deterred by the static electric field of the electric field screen.

\subsection{Insect-Capturing Function of the Single-Charged Dipolar Electric Field Screen}

Video Supplement 2B shows that the ICW of the S-screen can capture insects blown inside the electric field. This screen uses a strong force to capture various insect pests, including greenhouse pests [whitefly, green peach aphid, western flower thrip, tomato leaf-minor fly, green rice leaf hopper (Nephotettix cincticeps Uhler (Homoptera: Cicadellidae)), and shore fly (Scatella stagnalis Fallen (Diptera: Ephydridae))] (Foote, 1995; Helyer et al., 2004), warehouse and food processing factory pests [cigarette beetle (Lasioderma serricorne F. (Coleoptera: Anobiidae)), rice weevil (Sitophilus oryzae L. (Coleoptera: Curculionidae)), red flour beetle (Tribolium castaneum Herbst (Coleoptera: Tenebrionidae)), Adzuki bean weevil (Callosobruchus chinensis L. (Coleoptera: Bruchidae)), and vinegar fly (Drosophila melanogaster Meigen (Diptera: Drosophilidae))], museum pests [book louse (Liposcelis bostrychophila (Psocoptera: Liposcelididae))], and domestic pests [common clothes moth (Tineola bisselliella Humm. (Lepidoptera: Tineidae)), bathroom fly (Clogmia albipunctata (Diptera: Psychodidae)), German cockroach (Blattella germanica L. (Dictyoptera: Blattellidae)), Oriental termite (Nasutitermes matangensis (Isoptera: Termitidae), and Asian tiger mosquito (Aedes albopictus (Diptera: Culiciade))] (Hill, 1990; Foster \& Walker, 2002), indicating that our method is applicable to a wide range of pest control problems.

The major characteristic of the static electric field is the negative charge of the ICW, which creates a strong repulsive force for other negative charges in the electric field, pushing them toward the ground via the metal net. In this way, any conductor that enters the field is deprived of its free electrons and becomes positively charged. This phenomenon is called discharge-mediated positive electrification (of the conductor), and can be used to the insect itself and how it responds to the static electric field upon entering. Most insects possess a solid cuticle layer, which is the outer protective layer that covers the body. This layer is conductive (Ishay et al., 1992; McGonigle et al., 2002a; McGonigle \& Jackson, 2002b; Honna et al., 2008; Moussian, 2010). Consequently, an insect that enters a static electric field is deprived of free electrons in the cuticle layer and becomes positively charged (Figure 2D) (Kakutani et al., 2012b, 2012c; Nonomura et al., 2014b). Discharge-mediated positive electrification can be induced in actual insects, as the free electrons of the cuticle layer move to ground. A galvanometer for detecting electric current can be integrated into the ground circuit to detect this type of electron movement. Positively electrified insects are attracted to the central ICW (Figure 2E). The force is so strong that the captured insect cannot escape. This capturing mechanism is applicable to almost all insects, as they tend to possess conductive cuticle layers. Supplementary Table 1 shows the results of the insect-capturing assay. The results are summarized below. Larger voltages are required to capture larger pests. In all pests, higher voltages produce stronger forces for capture. Charging at $4.2 \mathrm{kV}$ was sufficient for capturing all of the pests tested in this study. The captured insects were held tightly and were not blown away with airflow at $7 \mathrm{~m} / \mathrm{s}$. Therefore, the electric field screens installed in the greenhouse were charged at $4.2 \mathrm{kV}$ for field experiments. 


\section{Configuration of a Model Greenhouse Completely Preventing the Pest entry}

\subsection{Installment of Electric Field Screens on the Side Windows of a Greenhouse}

The electric field screen first put to practical use was the single-charged dipolar type produced by our laboratory (Faculty of Agriculture, Kindai University) (Figure 3A) (Toyoda et al., 2019), and units were developed to install the screens on the side windows of the experimental greenhouse. The electric power consumed by the voltage generator was minimal, and could be provided by a standard lithium storage battery; normal alternating current (AC) domestic power sources could also be used. The screens were negatively charged at $4.2 \mathrm{kV}$, as described above. The ventilating fan was also covered with an electric field screen box to prevent pests from invading via the opening for the fan, especially when the fan was stopped (Figure 3A). The grounded metal net of the electric field screen was a stainless steel net with the same mesh size $(\sim 1.5 \mathrm{~mm})$ as a conventional woven insect net. Larger pests that cannot pass through this mesh were not tested, as they were prevented from entering by the net, without the need for an electric field screen.

In the S-screen, all parts are integrated into the main body (Supplementary Figure 2A, see Appendix A). This screen requires no special modifications or ground installation. The first S-screen produced by our laboratory consists of three units: ICWs held by a frame that integrates a negative voltage generator, two stainless net frames containing contact plugs and electric lines to the voltage generator, and a lithium battery. The lithium battery is installed on the surface of one of the net frames. The three unit frames are combined by simply placing the two net frames on either side of the ICW frame.

In laboratory-scale experiments, the ICW, which is the heart of the electric field screen, was made by passing a metal wire through a soft PVC tube. The electric field screen is easy to construct and there are no functional problems. In outdoor experiments with longer exposure periods, however, installed electric field screens are susceptible to discoloration, deformation, and cracking due to changes in temperature, humidity, and ultraviolet irradiation. These issues limit the practical implementation of electric field screens. In commercial electric field screens (single-charged dipolar type), the conductors are coated with PVC resin to prolong screen operation in outdoor environments with minimal deterioration (Toyoda et al., 2019). Such screens are built and sold by Sonoda Seisakusho (Osaka, Japan), a joint-stock company that designs, installs, inspects, and maintains electric field screens. A commercial electric field screen produced by Sonoda Seisakusho was installed in a greenhouse in Osaka Prefectural Research Institute of the Environment, Agriculture, and Fisheries (Supplementary Figure 2B, see Appendix A). It was constructed by welding multiple iron wires to an iron frame, coating it with PVC resin, and placing grounded metal nets on either side of the frame. Another marketable electric field screen is manufactured by Nabec (Panasonic Environment Engineering, Nagoya, Japan) and the ICW is produced by coating iron-expanded metal with PVC resin (Supplementary Figure 2C, see Appendix A). Grounded stainless steel nets with a diamond-shaped mesh were placed on each side (Toyoda et al., 2019). This electric field screen is also weatherproof, and can be used outside for long periods without performance deterioration.

\subsection{Construction of an Air-Oriented Anteroom With an Electric Field Screen}

In a greenhouse in which the side windows were equipped with S-screens, the problem of pest entry through the greenhouse door remains. To solve this problem, an anteroom was created to eliminate pests (Figure 3B) (Nonomura et al., 2014a). Ground net-free D-screens were installed in the anteroom in an attempt to create an ideal greenhouse that excluded all pests. Three types of electric field screen were installed in this anteroom: 1) a ground net-free, single-layer type with a yellow board on the wall opposite the entrance to the anteroom; 2) a ground net-free, single-layer type with a gray board at the entrance to the greenhouse, and 3) a single-layer type with a grounded metal net on one side on the wall opposite the greenhouse entrance (Figure 3B). A preliminary study indicated that whiteflies were preferentially trapped by the screen with the yellow board due to their photoselectivity.

The concept of an anteroom for eliminating pests combines the functions of electric field screens with regulation of the airflow in the room (Figure 4). This room was designed to generate airflow mechanically when the doors were opened, and to direct the airflow through the electric field screen (Nonomura et al., 2014a). To evaluate the effectiveness of this system, we blew air into the anteroom when the door was opened and simultaneously released whiteflies to examine the direction of the airflow and the capture of insects by the electric field screens (Figure 4A). More than $90 \%$ of the insects released were directed by the airflow and captured by the screen with the yellow board installed on the front wall. When there was no blowing air, although more time was needed, this screen attracted and trapped almost all of the insects. Next, air was automatically blown inside the anteroom when the greenhouse entrance was opened (Figure 4B). The airflow passed through the electric field screen to the opposite wall. The screen trapped the insects and pest-free air was directed into the greenhouse. This screen 
was furnished with a grounded metal net on one side to repel useful insects, such as pollinators, from inside the greenhouse.

A

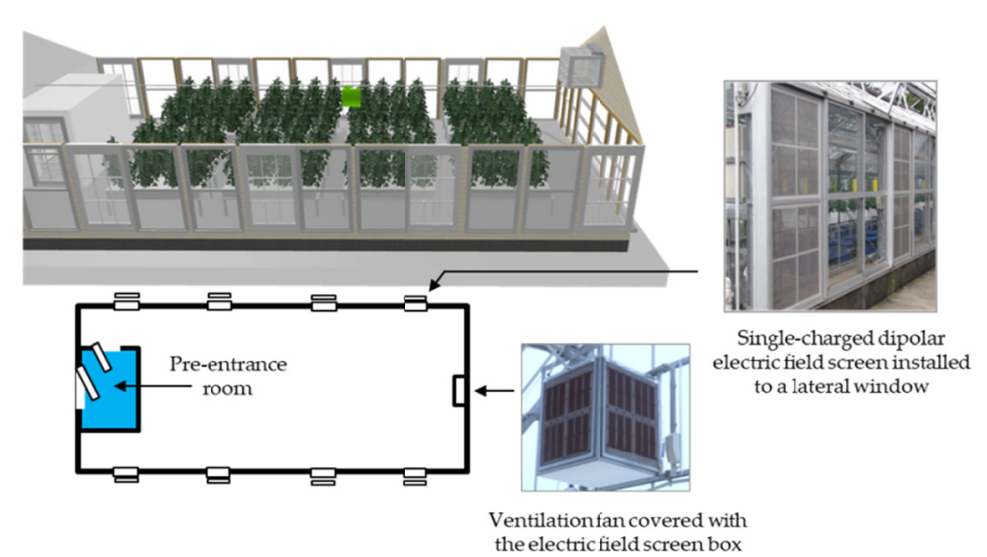

B

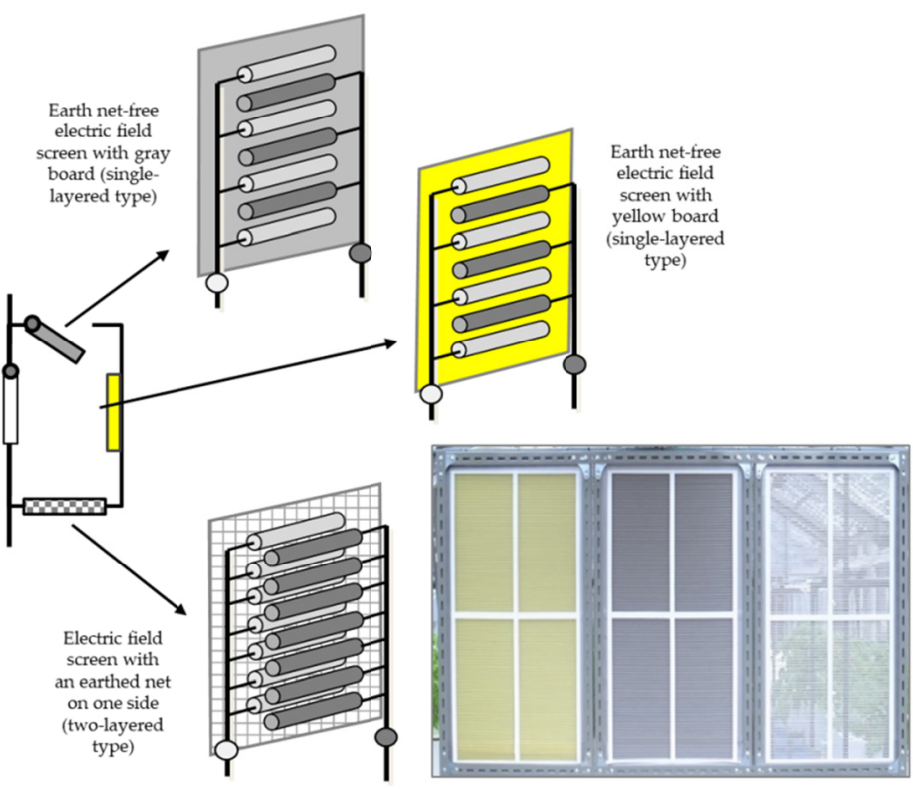

Figure 3. An ideal greenhouse that completely excludes pests (A) and the three types of electric field screens installed in the anteroom (B)

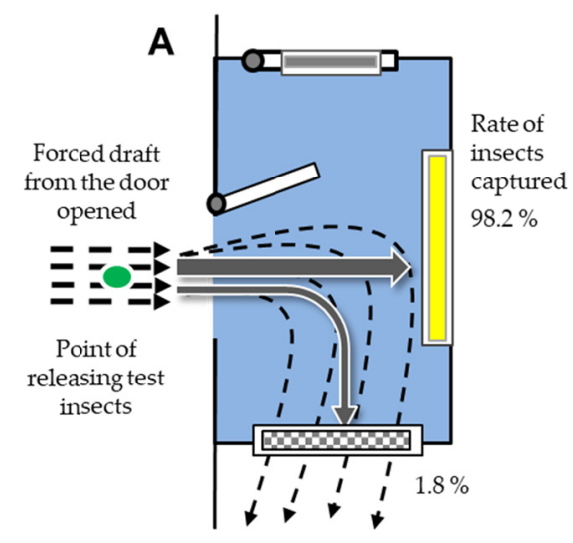

Direction of airflow

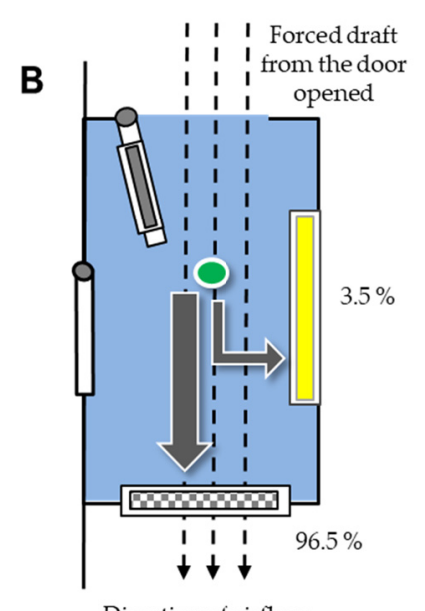

Direction of airflow

Figure 4. Schematic representation of pest elimination in an airflow-oriented anteroom with electric field screens 


\subsection{Supplementary Electrostatic Devices}

In a greenhouse in which the side windows and anteroom are furnished with electric field screens, the entry of pests through the windows is prevented. Nevertheless, there was a risk of invasion by insect pests that avoid the electric field screens installed in the greenhouse. The rate of pest invasion through the entrance is low; however, such entry cannot be neglected as secondary propagation of invading pests can lead to serious insect damage to cultivated plants. An electrostatic insect sweeper and electrostatic flying insect catcher are useful for eliminating these pests in the initial stage of invasion.

The second apparatus put into practical use was an electrostatic insect sweeper (Supplementary Figure 3A, see Appendix A) (Takikawa et al., 2015a). In this apparatus, a S-screen is wound around a cylindrical PVC pipe (Supplementary Figure 3B, see Appendix A). The non-grounded circuit was integrated such that no ground line was necessary. This apparatus is easy to operate in greenhouses (Supplementary Figures 3C and 3D, see Appendix A). The electrostatic insect sweeper is useful for trapping insect pests that frequently rest on leaf surfaces, such as whiteflies and aphids (Takikawa et al., 2015a). This apparatus was developed as a supplementary device for use in greenhouses guarded by electric field screens. The pest population can be reduced considerably by incorporating a sweeper as part of the routine care of cultivated plants. The electrostatic insect sweeper is also produced by Sonoda Seisakusho (Toyoda et al., 2019). The electrostatic insect sweeper has a non-grounded circuit that produces a static electric field in the space between the ICW and the non-grounded metal net. Insect pests are captured in this field. The size of the pests trapped varies with the charging voltage. Whiteflies and western flower thrips were captured with a $0.8 \mathrm{kV}$ charge, whereas green peach aphids, tomato leaf-miner flies, and shore flies required $1 \mathrm{kV}$ (Takikawa et al., 2015a). Insects are trapped easily after gently brushing the leaves they are resting on with the sweeper (Supplementary Figure 3B, see Appendix A). This approach is especially effective for trapping whiteflies, as they tend to stay on leaf surfaces for long periods (Supplementary Figure 3E, see Appendix A).

An electrostatic flying insect catcher (electrostatic racket) (Supplementary Figure 4, see Appendix A) (Takikawa et al., 2017c) is a device used to capture flying pests. It is carried by a greenhouse attendant during routine plant-care checks and is used to capture flying insects quickly, as they appear. It is possible to reduce the pest population significantly with continual, diligent use of the device. The catcher was developed to supplement the electric field screens, but is also useful in unprotected greenhouses. The area of the racket surface is easily modified so that the apparatus can be used in various facilities, such as food processing factories, warehouses, and facilities that provide meals in which the use of insecticides is strictly regulated or prohibited. Sonoda Seisakusho also makes a commercial electrostatic flying insect catcher (Toyoda et al., 2019).

\section{Evaluation of the Effectiveness of Pest Exclusion From a Greenhouse by Electrostatic Guarding}

In an actual greenhouse experiment, the greenhouse was separated into two rooms by a partition. In one of the rooms, the anteroom was furnished with D-screens, and all of the side windows were equipped with S-screens (negatively charged at 4.2 and $2 \mathrm{kV}$, respectively). The ventilating fan was also covered with an electric field screen box to prevent pests from invading via the opening for the fan, especially when the fan was stopped. The second room had no anteroom; no screens were installed on the side windows and it served as a control. We examined the entry of insect pests into both rooms. Each experiment lasted 2 weeks, and six experiments were conducted in total. In the greenhouse, blue and yellow adhesive plates were hung at constant intervals to trap any pests that invaded from the outside. Whiteflies, tomato leaf-minor flies, and green peach aphids are attracted to the color yellow, while the western flower thrip prefers blue. The number of pests trapped by the adhesive plates was counted to determine the number of pests in the greenhouse. In this experiment, we also carefully surveyed individual tomato plants cultured in the screen-furnished room to check for insects that may have hidden under plant leaves.

Over the course of the experiment, no green peach aphids or western flower thrips were found, while moderate to severe whitefly and tomato leaf-minor fly invasions were evident. As shown in Supplementary Table 3 (see Appendix B), both types of pests were completely prevented from entering the screen-installed room in all experiments. These experiments clearly demonstrated the practicality of the electric field screens. The severity of the pest invasion was clear from the number of pests trapped by the yellow adhesive plates hung inside the control room, and the experimental room would have been invaded similarly without the preventive measures. These results again demonstrate the effectiveness of electric field screens for pest control.

In this greenhouse study, the installed electric field screens effectively excluded the pests, and no supplementary devices (i.e., the electrostatic insect sweeper and electrostatic flying insect catcher) were required. Nevertheless, supplementary devices are an emergency measure when pests evade other means of trapping. 


\section{Conclusions and Future Perspectives}

Applied electrostatic engineering has successfully managed pathogens and insect pests affecting agricultural crops at various stages of crop production and preservation. Electrostatic principles have been applied in diverse ways, including for capturing spores and insects by exploiting the attractive force generated in a static electric field (without electric discharge) (Matsuda et al., 2006; Kakutani et al., 2017; Nonomura et al., 2014a; Matsuda et al., 2012; Matsuda et al., 2011; Takikawa et al., 2015; Moriura et al., 2006a, 2006b; Nonomura et al., 2009), repelling insects via their aversion to electric fields (Nonomura et al., 2012; Matsuda et al., 2011; Matsuda et al., 2015b), disinfecting bacterial and fungal pathogens using ozone produced through streamer discharge (Shimizu et al., 2007), instantaneously dislodging fungal pathogens from plants through exposure to a plasma stream produced via a corona discharge in the electric field (Nonomura et al., 2008), instantaneously pulverizing insects nesting in dried rice grains (Matsuda et al., 2018c), electrocuting virus-carrying mosquitoes in the screen by insect-mediated arch discharge (Kakutani et al., 2018), and negatively ionizing smoke particles in the ionic wind produced during corona discharge (Matsuda et al., 2018b). In this work, we used electrostatic devices to repel and capture insect pests, creating a pest-free space in a greenhouse with open windows. Based on these successful applications, we could realize a non-insecticidal pest control system for crop plants.

The electrostatic devices described here are patented inventions. The patent holders are Kindai University (Osaka, Japan), Kagome (Tokyo, Japan), Panasonic (Tokyo, Japan), and Osaka Prefecture (Osaka, Japan). Kindai University is in charge of managing the patent licenses and has prepared contracts for patent use. Contractors (including farmers) are allowed to make electric field screens (single-charged dipolar type) and related apparatuses (electrostatic insect sweeper, electrostatic flying insect catcher, electrostatic cabinet (Kakutani et al., 2017), and electrostatic seedling shelter (Takikawa et al., 2016)) for personal use or to produce and sell under specific agreements. Research that has a real impact on society has been our dream from the beginning. Therefore, the concepts and technologies originating from our university laboratory are made readily available to the public, in an effort to fulfill our mission of contributing to society by helping to solve real-world problems and move science forward. Our role will not change with greater recognition of this technology, and we will continue to research diligently and promote reliable techniques to improve the lives of others.

\section{Acknowledgments}

This work was supported by JSPS KAKENHI Grant Number 19K06299.

\section{References}

Brown, J. K. M. (2002). Comparative genetics of avirulence and fungicide resistance in the powdery mildew fungi. In R. R. Bélanger, et al. (Eds.), The Powdery Mildews (pp. 56-65). American Phytopathological Society Press: St. Paul, USA.

Cao, S., Yang, C., Gan, Y., \& Lu, Z. (2015). The health effects of passive smoking: An overview of systematic reviews based on observational epidemiological evidence. PLoS ONE, 10, e0139907. https://doi.org/ 10.1371/journal.pone.0139907

Cohen, S., \& Berlinger, M. J. (1986). Transmission and cultural control of white-fly borne viruses. Agric. Ecosyst. Environ, 17, 89-97. https://doi.org/10.1016/0167-8809(86)90030-7

Foote, B. A. (1995). Biology of shore flies. Ann. Rev. Entomol, 40, 417-442. https://doi.org/10.1146/annurev.en. 40.010195.002221

Foster, W. A., \& Walker, E. D. (2002). Mosquitoes (Culicidae). Medical and veterinary entomology (pp. 203-262). Elsevier Science, New York, USA.

Giancoli, D. C. (2005). Electric charge and electric field. In J. Challice (Ed.), Physics, Principles with Applications (pp. 39-469). Pearson Education International, London, UK.

Griffith, W. T. (2004). Electrostatic phenomena. In D. Bruflodt, \& B. S. Loehr (Eds.), The Physics of Everyday Phenomena, A Conceptual Introduction to Physics (pp. 232-252). McGraw-Hill, New York, USA.

Halliday, D., Resnick, R., \& Walker, J. (2005). Electric discharge and electric fields. In S. Johnson, \& E. Ford (Eds.), Fundamentals of Physics (pp. 561-604). John Wiley \& Sons, New York, USA.

Helyer, N., Brown, K., \& Cattlin, N. D. (2004). Pest profiles. In J. Northcott (Ed.), A colour handbook of biological control in plant protection (pp. 21-41). Manson Publishing, London, UK.

Hill, D. S. (1990). Pests of stored products and their control (pp. 1-274). Belhaven Press, London, UK. 
Honna, T., Akiyama, Y., \& Morishima, K. (2008). Demonstration of insect-based power generation using a piezoelectric fiber. Comp. Biochemi. Physiol. Part B: Biochem. Mol. Biol, 151, 460. https://oi.org/10.1016/ j.cbpb.2008.09.052

Horowitz, A. R., Kontsedalov, S., \& Ishaaya, I. (2004). Dynamics of resistance to the neonicotinoids acetamiprid and thiamethoxam in Bemisia tabacci (Homoptera: Aleyrodidae). J. Econ. Entomol, 97, 2051-2056. https://doi.org/10.1603/0022-0493-97.6.2051

Ishay, J. S., Shimony, T. B., Shalom, A. B., \& Kristianpoller, N. (1992). Photovoltaic effects in the oriental hornet, Vespa orientalis. J. Insect Physiol, 38, 37-48. https://doi.org/10.1016/0022-1910(92)90020-E

Jonassen, N. (2002). Electrostatic effects and Abatement of static electricity. Electrostatics (pp. 75-120). Kluwer Academic Publishers, Massachusetts, USA.

Jones, E., \& Childers, R. (2002). Electric charge and electric field. Physics (pp. 495-525). McGraw-Hill, Boston, USA.

Kakutani, K., Matsuda, Y., Haneda, K., Nonomura, T., Kimbara, J., Kusakari, S., ... Toyoda, H. (2012c). Insects are electrified in an electric field by deprivation of their negative charge. Ann. Appl. Biol., 160, $250-259$. https://doi.org/10.1111/j.1744-7348.2012.00538.x

Kakutani, K., Matsuda, Y., Haneda, K., Sekoguchi, D., Nonomura, T., Kimbara, J., ... Toyoda, H. (2012b). An electric field screen prevents captured insects from escaping by depriving bioelectricity generated through insect movements. J. Electrostat, 70, 207-211. https://doi.org/10.1016/j.elstat.2012.01.002

Kakutani, K., Matsuda, Y., Nonomura, T., Kimbara, J., Kusakari, S., \& Toyoda, H. (2012a). Practical application of an electric field screen to an exclusion of flying insect pests and airborne conidia from greenhouses with a good air penetration. J. Agric. Sci., 4, 51-60. https://doi.org/10.5539/jas.v4n5p51

Kakutani, K., Matsuda, Y., Takikawa, Y., Nonomura, T., Okada, K., Shibao, M., ... Toyoda, H. (2018). Electrocution of mosquitoes by a novel electrostatic window screen to minimize mosquito transmission of Japanese encephalitis viruses. Int. J. Sci. Res., 7, 47-50. Retrieved from https://www.worldwidejournals. com/international-journal-of-scientific-research-(IJSR)/file.php?val=May_2018_1525185202_265.pdf

Kakutani, K., Matsuda, Y., Takikawa, Y., Nonomura, T., Okada, K., Shibano, M., ... Toyoda, H. (2017). Successful single-truss cropping cultivation of healthy tomato seedlings raised in an electrostatically guarded nursery cabinet with non-chemical control of whiteflies. Glob. J. Pest. Dis. Crop Prot, 5, 269-275. Retrieved from http://www.globalscienceresearchjournals.org

Kaneko, Y., Motohashi, Y., Nakamura, H., Endo, T., \& Eboshida, A. (2005). Increasing prevalence of Japanese cedar pollinosis: A meta-regression analysis. Int. Arch. Allergy Immunol., 136, 365-371. https://doi.org/ $10.1159 / 000084256$

Kashimoto, K., Sameshima, T., Matsuda, Y., Nonomura, T., Oichi, W., Kakutani, K., ... Toyoda, H. (2003). Infectivity of a Japanese isolate of Oidium neolycopersici KTP-01 to a European tomato cultivar resistant to O. lycopersici. J. Gen. Plant Pathol, 69, 406-408. https://doi.org/10.1007/s10327-003-0070-y

Kiss, L., Cook, R. T. A., Saenz, G. S., Cunnington, J. H., Takamatsu, S., Pascoe, I., ... Rossman, A. Y. (2001). Identification of two powdery mildew fungi, Oidium neolycopersici sp. nov. and $O$. lycopersici, infecting tomato in different parts of the world. Mycol. Res., 105, 684-697. https://doi.org/10.1017/S09537562 01004105

Lebeda, A., \& Mieslerová, B. (2002). Variability in pathogenicity of Oidium neolycopersici on Lycopersicon species. J. Plant Dis Prot, 109, 129-141. Retrieved from https://www.jstor.org/stable/43216189

Lindhout, P., Pet, G., \& van der Beek, H. (1994). Screening wild Lycopersicon species for resistance to powdery mildew (Oidium lycopersicum). Euphytica, 72, 43-49. https://doi.org/10.1007/BF00023771

Matsuda, Y., \& Toyoda, H. (2018a). Novel electrostatic devices for managing biotic and abiotic nuisances in environments. Open Access J. Sci., 2, 337-353. 109.

Matsuda, Y., Ikeda, H., Moriura, N., Tanaka, N., Shimizu, K., Oichi, W., ... Toyoda, H. (2006). A new spore precipitator with polarized dielectric insulators for physical control of tomato powdery mildew. Phytopathology, 96, 967-974. https://doi.org/10.1094/PHYTO-96-0967

Matsuda, Y., Kakutani, K., Nonomura, T., Kimbara, J., Kusakari, S., Osamura, K., \& Toyoda, H. (2012). An oppositely charged insect exclusion screen with gap-free multiple electric fields. J. Appl. Phys., 112, 116103(-1)-116103(-3). https://doi.org/10.1063/1.4767635 
Matsuda, Y., Kakutani, K., Nonomura, T., Kimbara, J., Osamura, K., Kusakari, S., \& Toyoda, H. (2015a). Safe housing ensured by an electric field screen that excludes insect-net permeating haematophagous mosquitoes carrying human pathogens. J. Phys. (Conference Series), 646, 0120021-0120024. Retrieved from http://iopscience.iop.org/article/10.1088/1742-6596/646/1/012002

Matsuda, Y., Mori, Y., Nishida, M., Sakano, S., Tarumoto, K., Nonomura, T., ... Toyoda, H. (2005). Screening of wild Lycopersicon species for resistance to Japanese isolate of tomato powdery mildew Oidium neolycopersici. Breeding Sci., 55, 355-360. https://doi.org/10.1270/jsbbs.55.355

Matsuda, Y., Nonomura, T., Kakutani, K., Kimbara, J., Osamura, K., Kusakari, S., \& Toyoda, H. (2015b). Avoidance of an electric field by insects: Fundamental biological phenomenon for an electrostatic pest-exclusion strategy. J. Phys. (Conference Series), 646, 0120031-0120034. Retrieved from http://iopscience.iop.org/article/10.1088/1742-6596/646/1/012003

Matsuda, Y., Nonomura, T., Kakutani, K., Takikawa, Y., Kimbara, J., Kasaishi, Y., ... Toyoda, H. (2011). A newly devised electric field screen for avoidance and capture of cigarette beetles and vinegar flies. Crop Prot., 30, 155-162. Retrieved from http://iopscience.iop.org/article/10.1088/1742-6596/646/1/012003/meta

Matsuda, Y., Takikawa, Y., Nonomura, T., Kakutani, K., Okada, K., Shibao, M., ... Toyoda, H. (2018b). A simple electrostatic device for eliminating tobacco sidestream to prevent passive smoking. Instruments, 2(3), 1-10. https://doi.org/10.3390/instruments2030013

Matsuda, Y., Takikawa, Y., Nonomura, T., Kakutani, K., Okada, K., Shibao, M., ... Toyoda, H. (2018c). Selective electrostatic eradication of Sitopholus oryzae nesting in stored rice. J. Food Technol. Preserv., 2, 15-20. Retrieved from http://www.alliedacademies.org/articles/selective-electrostatic-eradication-of-sitophilus-ory zae-nesting-in-stored-rice-10076.html

McGonigle, D. G., \& Jackson, C. W. (2002b). Effect of surface material on electrostatic charging of houseflies (Musca domestica L). Pest Manag. Sci., 58, 374-380. https://doi.org/10.1002/ps.463

McGonigle, D. G., Jackson, C. W., \& Davidson, J. L. (2002a). Triboelectrification of houseflies (Musca domestica L.) walking on synthetic dielectric surfaces. J. Electrostat., 54, 167-177. https://doi.org/10.1016/ S0304-3886(01)00177-2

Mieslerová, B., Lebeda, A., \& Chetelat, R. T. (2000). Variation in response of wild Lycopersicon and Solanum spp. against tomato powdery mildew (Oidium lycopersici). J. Phytopathol., 148, 303-311. https://doi.org/10.1046/j.1439-0434.2000.00492.x

Moriura, N., Matsuda, Y., Oichi, W., Nakashima, S., Hirai, T., Nonomura, T., ... Toyoda, H. (2006b). An apparatus for collecting total conidia of Blumeria graminis f. sp. hordei from leaf colonies using electrostatic attraction. Plant Pathol., 55, 367-374.11. https://doi.org/10.1111/j.1365-3059.2006.01356.x

Moriura, N., Matsuda, Y., Oichi. W., Nakashima, S., Hirai, T., Sameshima, T., ... Toyoda, H. (2006a). Consecutive monitoring of lifelong production of conidia by individual conidiophores of Blumeria graminis f. sp. hordei on barley leaves by digital microscopic techniques with electrostatic micromanipulation. Mycol. Res., 110, 18-27. https://doi.org/10.1016/j.mycres.2005.09.007

Moussian, B. (2010). Recent advances in understanding mechanisms of insect cuticle differentiation. Insect Biochem. Mol. Biol., 40, 363-375. https://doi.org/10.1016/j.ibmb.2010.03.003

Nauen, R., \& Denholm, I. (2005). Resistance of insect pests to neonicotinoid insecticides: Current status and future respects. Adv. Insects Biochem. Physiol., 58, 200-215. https://doi.org/10.1002/arch.20043

Nonomura, T., Matsuda, Y., Kakutani, K., Kimbara, J., Osamura, K., Kusakari, S., \& Toyoda, H. (2014b). Electrostatic measurement of dischargeable electricity and bioelectric potentials produced by muscular movements in flies. J. Electrostat., 72, 1-5. https://doi.org/10.1016/j.elstat.2013.10.012

Nonomura, T., Matsuda, Y., Kakutani, K., Kimbara, J., Osamura, K., Kusakari, S., \& Toyoda, H. (2012). An electric field strongly deters whiteflies from entering window-open greenhouses in an electrostatic insect exclusion strategy. Europ. J. Plant Pathol., 134, 661-670. https://doi.org/10.1007/s10658-012-0014-5

Nonomura, T., Matsuda, Y., Kakutani, K., Takikawa, Y., \& Toyoda, H. (2008). Physical control of powdery mildew (Oidium neolycopersici) on tomato leaves by exposure to corona discharge. Can. J. Plant Pathol., 30, 517-524. https://doi.org/10.1080/07060660809507551 
Nonomura, T., Matsuda, Y., Kakutani, K., Takikawa, Y., Kimbara, J., Osamura, K., ... Toyoda, H. (2014a). Prevention of whitefly entry from a greenhouse entrance by furnishing an airflow-oriented pre-entrance room guarded with electric field screens. J. Agric. Sci., 6, 172-184. https://doi.org/10.5539/jas.v6n12p172

Nonomura, T., Matsuda, Y., Xu, L., Kakutani, K., Takikawa, Y., \& Toyoda, H. (2009). Collection of highly germinative pseudochain conidia of Oidium neolycopersici from conidiophores by electrostatic attraction. Mycol. Res., 113, 364-372. https://doi.org/10.1016/j.mycres.2008.11.012

Oliveira, M. R. V., Henneberry, T. J., \& Anderson, P. (2001). History, current status, and collaborative research projects for Bemisia tabaci. Crop Prot., 20, 709-723. https://doi.org/10.1016/S0261-2194(01)00108-9

Palumbo, J. C., Horowitz, A. R., \& Prabhaker, N. (2001). Insecticidal control and resistance management for Bemisia tabaci. Crop Prot., 20, 739-765. https://doi.org/10.1016/S0261-2194(01)00117-X

Perring, T. M. (2001). The Bemisia tabaci species complex. Crop Prot., 20, 725-737. https://doi.org/ 10.1016/S0261-2194(01)00109-0

Prabhaker, N., Coudriet, D. L., \& Meyerdirk, D. E. (1985). Insecticide resistance in the sweetpotato whitefly, Bemisia tabaci (Homoptera: Aleyrodiae). J. Econ. Entomol., 78, 748-752. https://oi.org/10.1093/ jee/78.4.748

Saulyte, J., Regueira, C., Montes-Martínez, A., Khudyakov, P., \& Takkouch, B. (2014). Active or passive exposure to tobacco smoking and allergic rhinitis, allergic dermatitis, and food allergy in adults and children: A systematic review and meta-analysis. PLoS Med., 13, e1001939. https://doi.org/10.1371/journal.pmed. 1001611

Schlesinger, R. B. (2007). The Health Impact of Common Inorganic Components of Fine Particulate Matter (PM2.5) in Ambient Air: A Critical Review. Inhal. Toxicol., 19, 811-832. https://doi.org/10.1080/08958370 701402382

Sharaf, N. (1986). Chemical control of Bemisia tabaci. Agric. Ecosyst. Environ., 17, 111-127. https://oi.org/ 10.1016/0167-8809(86)90032-0

Shimizu, K., Matsuda, Y., Nonomura, T., Ikeda, H., Tamura, N., Kusakari, S., ... Toyoda, H. (2007). Dual protection of hydroponic tomatoes from rhizosphere pathogens Ralstonia solanacearum and Fusarium oxysporum f. sp. radicis-lycopersici and airborne conidia of Oidium neolycopersici with an ozone-generative electrostatic spore precipitator. Plant Pathol., 56, 987-997. https://doi.org/10.1111/ j.1365-3059.2007.01681.x

Takikawa, Y., Matsuda, Y., Kakutani, K., Nonomura, T., Kusakari, S., Ito, H., ... Toyoda, H. (2015a). Electrostatic insect sweeper for eliminating whiteflies colonizing host plants; a complementary pest control device in an electric field screen-guarded greenhouse. Insects., 6, 442-454. https://doi.org/10.3390/ insects6020442.

Takikawa, Y., Matsuda, Y., Nonomura, T., Kakutani, K., Kimbara, J., Osamura, K., ... Toyoda, H. (2014). Electrostatic guarding of bookshelves from mould-free preservation of valuable library books. Aerobiologia 30, 435-444. https://doi.org/10.1007/s10453-014-9340-8

Takikawa, Y., Matsuda, Y., Nonomura, T., Kakutani, K., Kusakari, S., \& Toyoda, H. (2017a). An electrostatic-barrier-forming window that captures airborne pollen grains to prevent pollinosis. Int. J. Environ. Res. Pub. Health., 14, 1-5. https://doi.org/10.3390/ijerph14010082

Takikawa, Y., Matsuda, Y., Nonomura, T., Kakutani, K., Kusakari, S., \& Toyoda, H. (2017b). Electrostatic elimination of fine smoke particles by a newly devised air purification screen. Int. J. Sci. Res. Environ. Sci., 51, 17-21. https://doi.org/10.12983/ijsres-2017-p0017-0021

Takikawa, Y., Matsuda, Y., Nonomura, T., Kakutani, K., Kusakari, S., Okada, K., \& Toyoda, H. (2016). An electrostatic nursery shelter for safely raising pest-free and pathogen-free tomato seedlings in a window-open greenhouse. J. Agric. Sci., 8, 13-25. https://doi.org/10.5539/jas.v8n4p13

Takikawa, Y., Matsuda, Y., Nonomura, T., Kakutani, K., Okada, K., Shibano, M., ... Toyoda, H. (2017c). Elimination of whiteflies colonizing greenhouse tomato plants using an electrostatic flying insect catcher. Int. J. Cur. Adv. Res., 6, 5517-5521. https://doi.org/10.24327/ijcar.2017.5521.0742

Takikawa, Y., Matsuda, Y., Nonomura, T., Kakutani, Kusakari, S., \& Toyoda, H. (2019). Exclusion of flying insect pests from a plastic hoop greenhouse by a bamboo blind-type electric field screen. Int. J. Pest. Manage (submitted). 
Takikawa, Y., Matsuda. Y., Nonomura, T., Kakutani, K., Kusakari, S., \& Toyoda, H. (2015). Electrostatic trap with an insect discharge recorder for multiple real-time monitoring of pests prowling in a warehouse. Int. J. Adv. Agric. Res., 3, 55-63. Retrieved from http://www.bluepenjournals.org/ijaar/contents/2015/October/ Vol._3_Issue_6.php

Tanaka, N., Matsuda, Y., Kato, E., Kokabe, K., Furukawa, T., Nonomura, T., ... Toyoda, H. (2008). An electric dipolar screen with oppositely polarized insulators for excluding whiteflies from greenhouses. Crop Prot., 27, 215-221. https://doi.org/10.1016/j.cropro.2007.05.009

Toyoda, H., \& Matsuda, Y. (2015b). Electric field screen: Principles and applications (pp. 1-238). Nobunkyo Production, Tokyo, Japan.

Toyoda, H., Kusakari, K., Matsuda, Y., Kakutani, K., Xu, L., Nonomura, T., \& Takaikawa, Y. (2019). An illustrated manual of electric field screens: Their structures and functions (pp. 1-112). RAEFSS Publishing, Nara, Japan.

Toyoda, H., Matsuda, Y., Nonomura, T., \& Ouchi, S. (2000). Molecular approaches to chemical and biological control of bacterial wilt pathogen of tomato. Plant diseases and their control (pp. 79-82). China Agricultural Scientech Press, Beijing, China.

Toyoda, H., Matsuda, Y., Nonomura, T., Kakutani, K., \& Takaikawa, Y. (2015a). Comprehensive approaches to crop protection (pp. 1-316). RAEFSS Publishing, Nara, Japan.

Ueda, S., \& Brow, J. K. (2006). First report of the Q biotype of Bemisia tabaci in Japan by mitochondrial cytochrome oxidase I sequence analysis. Phytoparasitica., 34, 405-411. Retrieved from http://www. phytoparasitica.org posting July 21, 2006

van der Beek, J. G., Pet, G., \& Lindhout, P. (1994). Resistance to powdery mildew (Oidium lycopersicum) in Lycopersicon hirsutum is controlled by an incompletely-dominant gene Ol-1 on chromosome 6. Theor. Appl. Genet., 89, 467-473. https://doi.org/10.1007/BF00225382

Wegner, H. E. (2002). Electrical charging generators. In E. Geller, et al. (Eds.), McGraw-Hill Encyclopedia of Science and Technology (9th ed., pp. 42-43). The Lakeside Press, New York, USA.

Weintrub, P. G., \& Berlinger, M. J. (2004). Physical control in greenhouses and field crops. In A. R. Horowitz, \& I. Ishaaya (Eds.), Insect Pest Management (pp. 301-318). Springer-Verlag, Amsterdam, Netherland.

\section{Appendix}

Video Supplements 1 and 2: Test insect pests (whiteflies, western flower thrips, green peach aphids, and tomato leaf minor flies) captured with the insulated conductor wires (ICWs) of D-screens (https://www.dropbox.com/s/tg49jf37ptwt1es/JAS Video supplement 1.mp4?dl=0) and whiteflies captured and repelled with a S-screen (https://www.dropbox.com/s/a6k54upt0y4dzbz/JAS Video Supplement 2.mp4?dl=0).

Supplementary Figures 1-4: Structure and function of voltage generators (1) and the marketable electrostatic devices developed (2-4).

Supplementary Tables 1-3: List of voltages applied to the single- and double-charged dipolar electric field screens (S-screens and D-screens, respectively) to capture all test insects blown toward the insulated conductor wires at different wind speeds (1); list of insects examined in terms of their avoidance of the electric field of the S-screen (2); and the results of a pest exclusion assay in a greenhouse, in which the side windows and anteroom were furnished with S- and D-screens, respectively (3). 
Supplementary figure 1. Schematic representation of structure and function of negative (A) and positive (B) voltage generators in an electric driver part and earthed (C) and non-earthed circuit (D, E) integrated in single- and doublecharged types of the electric field screen.

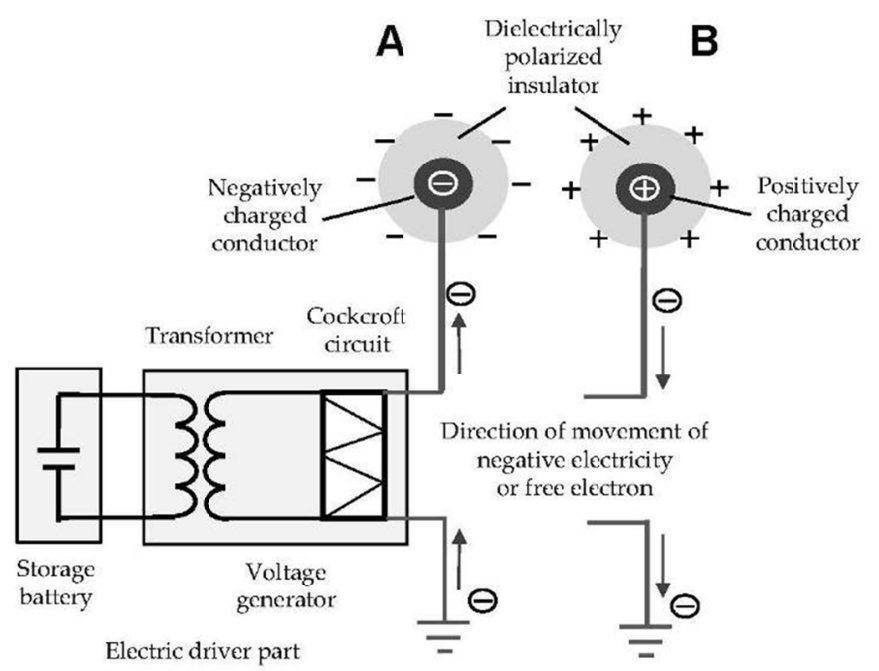

C

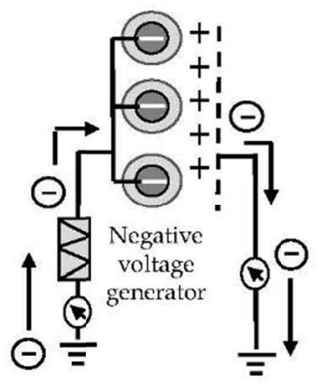

D

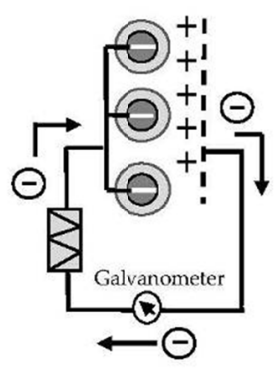

$\mathbf{E}$

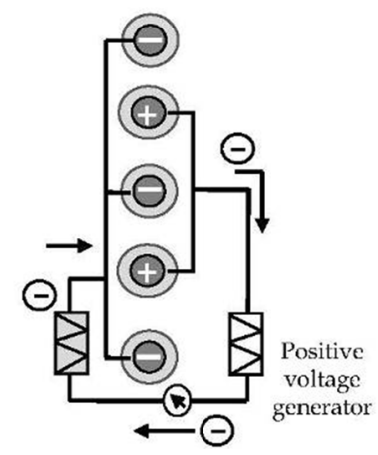


Supplementary figure 2. Schematic representation of the independent type of single-charged dipolar electric field screen consisting of three units $(A)$ and practically applied marketable single-charged dipolar electric field screens to a greenhouse facility of Osaka Prefectural Research Institute of Environment, Agriculture and Fisheries (B) and an experimental greenhouse of Faculty of Agriculture, Kindai University (C)..
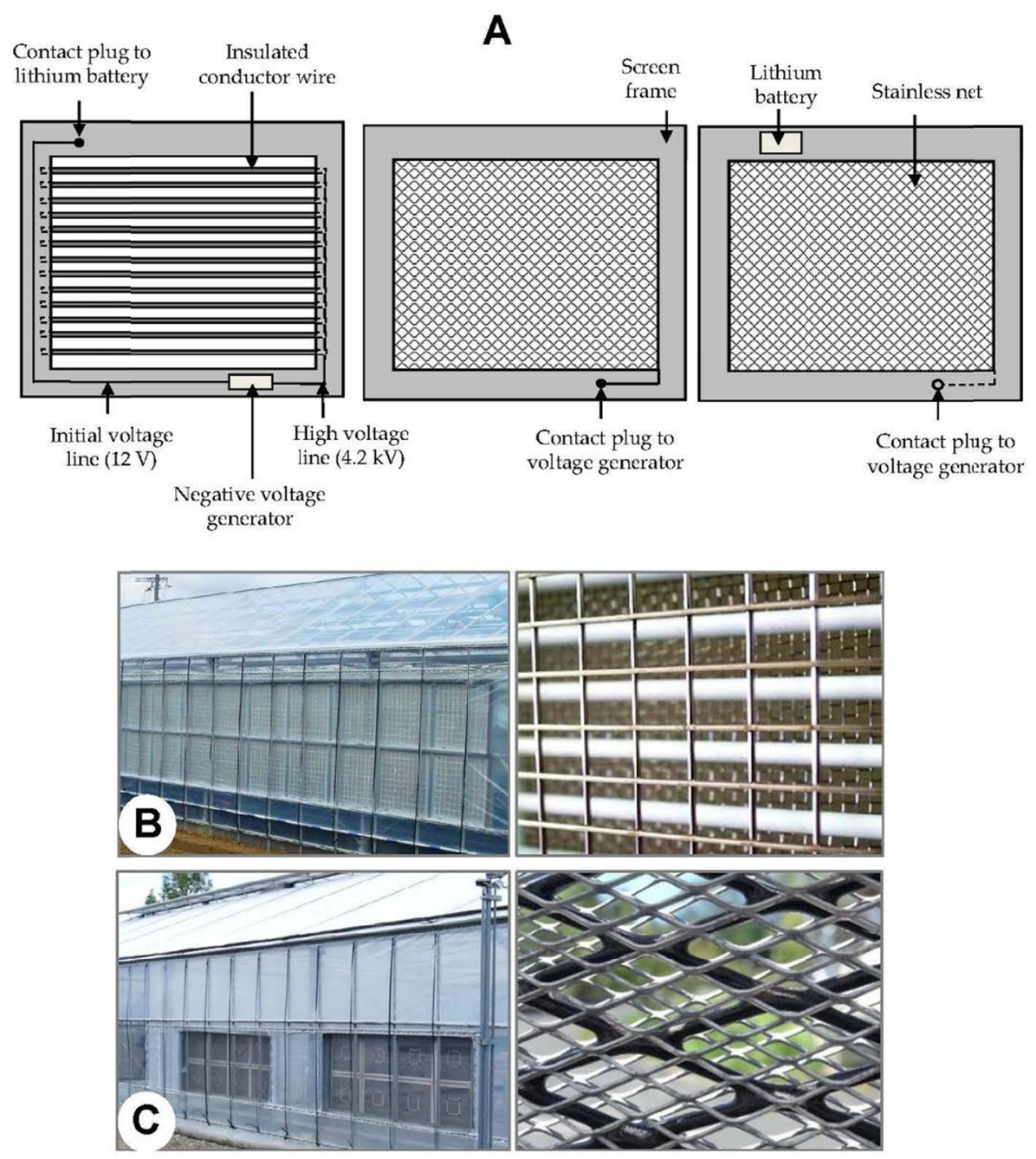
Supplementary figure 3. (A) Schematic representation of a structure of an electrostatic insect sweeper and (B) inner structure of the electrostatic insect sweeper and capture of insects on a plan leaf, and (C) photographic demonstration of electrostatic insect sweeper used for trapping insects resting on leaves of greenhouse tomatoes and (D) whiteflies trapped with insulated conductor wires of the electrostatic insect sweeper.

A

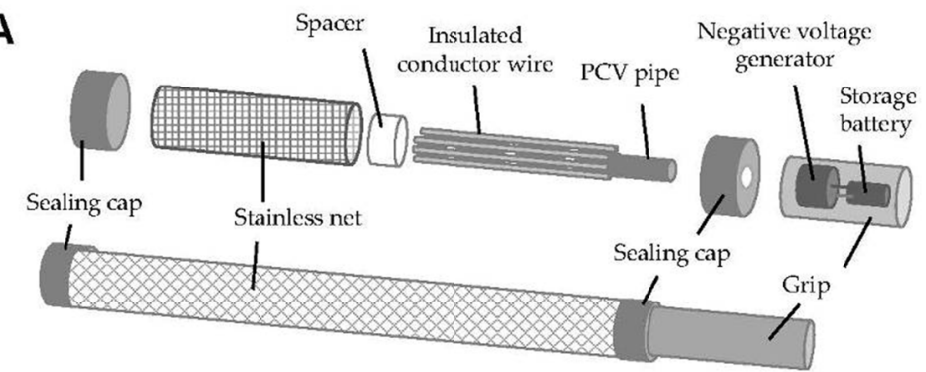

B
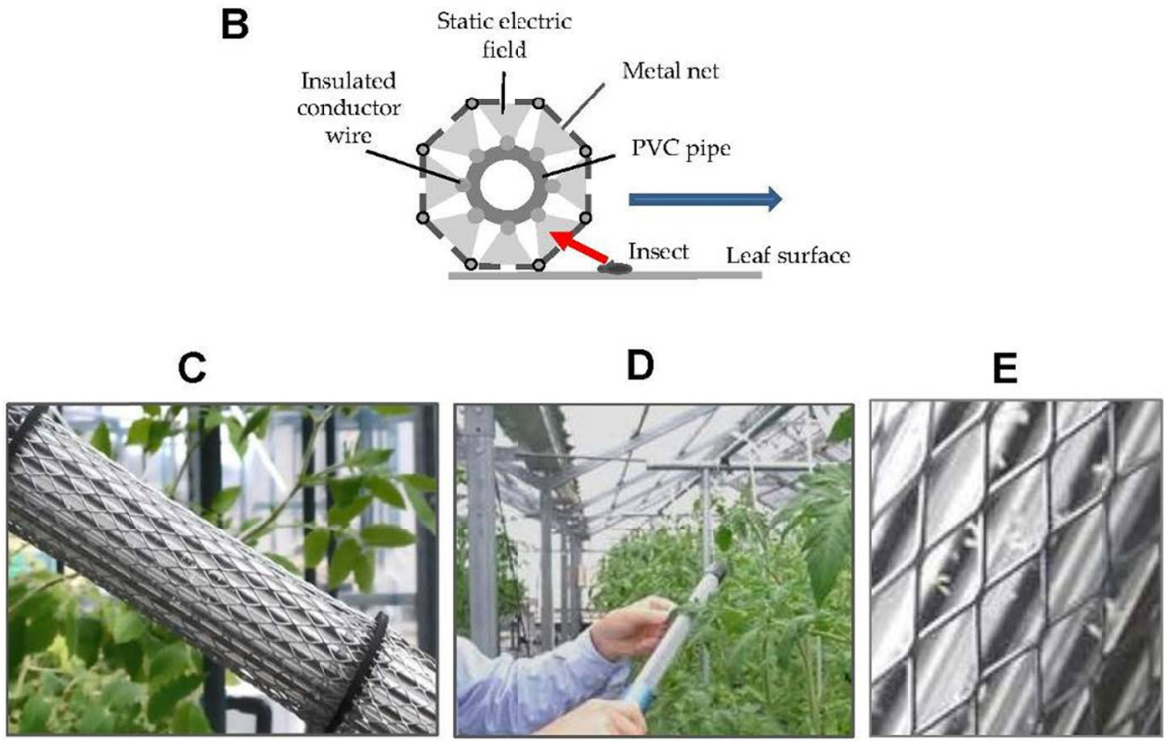
Supplementary figure 4. Photographic and schematic representation of an electrostatic flying insect catcher.
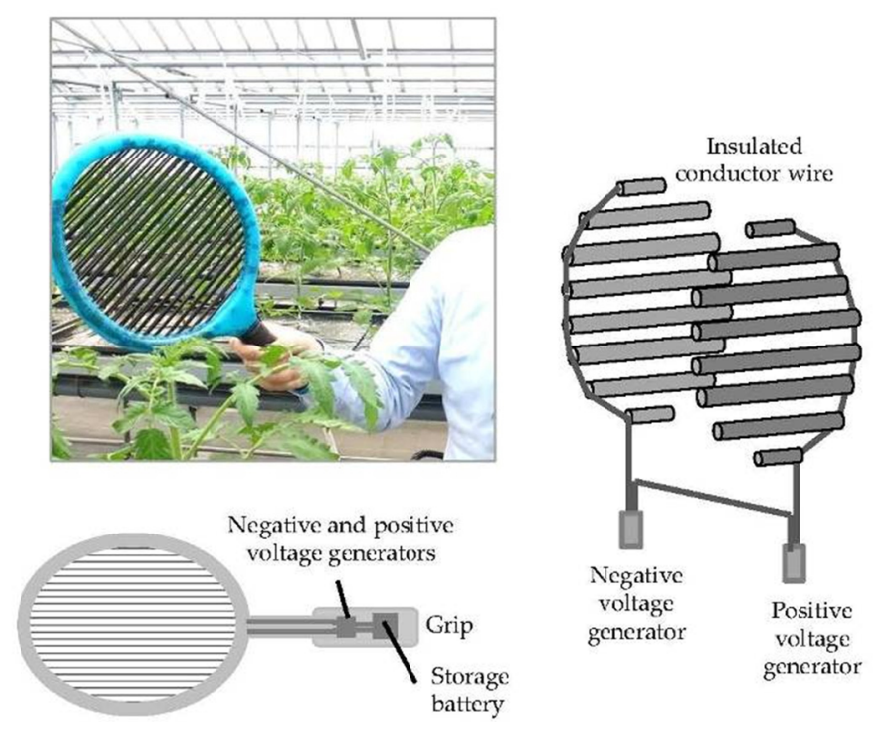

Supplementary table 1. Capture of insect pests blown toward the insulated conductor wires by double- and single-charged dipolar electric field screens

\begin{tabular}{|c|c|c|c|c|}
\hline \multirow{3}{*}{$\begin{array}{l}\text { Insect pests } \\
\text { tested }\end{array}$} & \multicolumn{4}{|c|}{ Voltage required to completely capture insects $(\mathrm{kV})$} \\
\hline & \multicolumn{3}{|c|}{ Double-charged type } & \multirow{2}{*}{$\frac{\text { Single-charged type }}{5^{\mathrm{a}}}$} \\
\hline & 1 & 2 & 3 & \\
\hline Whiteflies & 0.8 & 1.0 & 1.2 & 2.7 \\
\hline Green peach aphids & 1.0 & 1.0 & 1.2 & 3.2 \\
\hline Western flower thrips & 1.5 & 2.0 & 2.0 & 4.2 \\
\hline Tomato leaf-minor flies & 1.2 & 1.5 & 1.5 & 4.2 \\
\hline
\end{tabular}

aWind velocity of blowing $(\mathrm{m} / \mathrm{sec})$ 
Supplementary table 2. Insects avoiding a dipolar electric field

\begin{tabular}{|c|c|c|c|c|}
\hline Order & Family & Genus and species & Common name & $\begin{array}{c}\text { Voltage (kV) of } \\
\text { avoidance }\end{array}$ \\
\hline \multirow[t]{29}{*}{ Coleoptera } & Anobiidae & Lasioderma serricorne & Cigarette beetle & 0.8 \\
\hline & Attelabidae & Euops splendidus & Leaf-rolling weevil & 1.8 \\
\hline & Bruchidae & Callosobruchus chinensis & Adzuki bean weevil & 1.2 \\
\hline & \multirow{2}{*}{ Cerambycidae } & Chlorophorus annularis & Bamboo longicorn beetle & 2.8 \\
\hline & & Phytoecia rufiventris & Chrysanthemum longicorn beetle & 1.9 \\
\hline & \multirow{9}{*}{ Chrysomelidae } & Argopistes coccinelliformis & Ladybug mimicking leaf beetle & 3.2 \\
\hline & & Aulacophora femoralis & Cucurbit leaf beetle & 1.3 \\
\hline & & Chrysolina aurichalcea & Mugwort leaf beetle & 1.9 \\
\hline & & Gallerucida bifasciata & Dioscorea leaf beetle & 2.8 \\
\hline & & Gastrophysa atrocyanea & Japanese green duck leaf beetle & 1.2 \\
\hline & & Gonioctena rubripennis & Wisteria leaf beetle & 2.8 \\
\hline & & Lema cirsicola & Leaf beetle & 2.8 \\
\hline & & Ophraella communa & Ragweed leaf beetle & 1.2 \\
\hline & & Coccinella septempunctata & Seven-spotted ladybird beetle & 2.4 \\
\hline & \multirow{4}{*}{ Coccinellidae } & Aiolocaria hexaspilota & Ladybird beetle & 1.2 \\
\hline & & Epilachna vigintioctopunctata & Twentyeight-spotted ladybird beetle & 2.4 \\
\hline & & Harmonia axyridis & Asian ladybird beetle & 2.1 \\
\hline & & Anosimus decoratus & Weevil & 2.5 \\
\hline & \multirow{3}{*}{ Curculionidae } & Episomus turritus & Weevil & 4.3 \\
\hline & & Eugnathus distinctus & Weevil & 3.2 \\
\hline & & Nesalcidodes trifidus & Snout weevil & 4.3 \\
\hline & Elateridae & Pectocera fortunei & Click beetle & 2.1 \\
\hline & Meloidae & Epicauta gorhami & Blister beetle & 0.4 \\
\hline & Mordellidae & Mordella brachyura & Tumbling flower beetle & 3.2 \\
\hline & Oedemeridae & Xanthochroa atriceps & False blister beetle & 4.5 \\
\hline & Rhynchophoridae & Sitophilus oryzae & Rice weevil & 4.5 \\
\hline & & Plesiophthalmus nigrocyaneus & Mimawari beetle & 4.5 \\
\hline & Tenebrionidae & Tribolium castaneum & Red flour beetle & 2.4 \\
\hline & & Uloma latimanus & Black fungus beetle & 0.5 \\
\hline \multirow[t]{7}{*}{ Hemiptera } & Aleyrodidae & Bemisia tabaci & Sweet potato whitefly & 0.9 \\
\hline & Aphididae & Myzus persicae & Green peach aphid & 1.5 \\
\hline & Cicadellidae & Nephotettix cincticeps & Green rice leafhopper & 0.3 \\
\hline & Tettigellidae & Bothrogonia ferruginea & Black tipped leafhopper & 0.5 \\
\hline & \multirow{2}{*}{ Lygaeidae } & Geocoris varius & Large white-spotted seed bug & 1.2 \\
\hline & & Metochus abbreviatus & Large white-spotted seed bug & 0.8 \\
\hline & Pentatomidae & Eurydema rugosa & Cabbage bug & 1.1 \\
\hline \multirow[t]{6}{*}{ Diptera } & Agromyzidae & Liriomyza sativae & Tomato leaf minor & 1.2 \\
\hline & Bibionidae & Bibio japonicus & Love bug & 0.8 \\
\hline & Culicidae & Aedes albopictus & Asian tiger mosquito & 0.5 \\
\hline & Drosophilidae & Drosophila melanogaster & Vinegar fly & 1.7 \\
\hline & Ephydridae & Scatella stagnalis & Greenhouse shore fly & 1.7 \\
\hline & Psychodidae & Clogmia albipunctatus & Bath room fly & 1.7 \\
\hline \multirow[t]{4}{*}{ Hymenoptera } & Anthophoridae & Tetralonia nipponensis & Long-horned bee & 1.6 \\
\hline & Chalcididae & Brachymeria lasus & Chalcid wasp & 0.9 \\
\hline & Formicidae & Formica japonica & Japanese wood ant & 0.2 \\
\hline & Sphecidae & Sphex argentatus & Digger wasps & 4.2 \\
\hline \multirow[t]{2}{*}{ Lepidoptera } & Geometridae & Biston robustus & Lilac beauty & 1.4 \\
\hline & Tineidae & Tineola bisselliella & Common clothes moth & 1.4 \\
\hline \multirow[t]{2}{*}{ Blattodea } & Blattellidae & Blattella germanica & German cockroach & 1.8 \\
\hline & Blattidae & Neostylopyga rhombifolia & Harlequin cockroach & 1.2 \\
\hline Thysanoptera & Thripidae & Frankliniella occidentalis & Western flower thrips & 1.2 \\
\hline Mantodea & Mantidae & Tenodera aridifolia & Praying mantis & 0.7 \\
\hline Psocoptera & Liposcelidae & Liposcelis bostrychophilus & Book louse & 0.6 \\
\hline Dermaptera & Anisolabididae & Dermaptera sp. & Earwig & 0.7 \\
\hline \multirow{3}{*}{$\begin{array}{l}\text { Orthoptera } \\
\text { Isopoda }\end{array}$} & Tetrigoidea & Acridium japonicum & Bolivar & 1.1 \\
\hline & Armadillidiidae & Armadillidium vulgare & Pill bug & 1.6 \\
\hline & Rhinotermitidae & Coptotermes formosanus & Oriental termite & 1.6 \\
\hline \multirow[t]{5}{*}{ Araneae } & Araneus & Araneus ventricosus & Orb-weaving spider & 2.2 \\
\hline & Pardosa & Pardosa astrigera & Wolf spider & 2.1 \\
\hline & Pisauridae & Dolomedes sulfureus & Fishing spider & 2.3 \\
\hline & Thomisidae & Thomisus labefactus & Crab spider & 2.8 \\
\hline & Uloboridae & Octonoba varians & Zebra spider & 2.3 \\
\hline
\end{tabular}


Supplementary table 3. Exclusion of insect pests from a greenhouse furnished with single-charged dipolar electric field screens

\begin{tabular}{|c|c|c|c|c|c|c|c|}
\hline \multirow{2}{*}{$\begin{array}{l}\text { Test insect } \\
\text { pests }\end{array}$} & \multirow{2}{*}{$\begin{array}{l}\text { Installment of } \\
\text { single-charged } \\
\text { dipolar electric } \\
\text { field screens }\end{array}$} & \multicolumn{6}{|c|}{ Number of pests entering the rooms } \\
\hline & & 1 & 2 & 3 & 4 & 5 & $6^{\mathrm{a}}$ \\
\hline \multirow[t]{2}{*}{ Whiteflies } & yes & 0 & 0 & 0 & 0 & 0 & 0 \\
\hline & no & 4285 & 6583 & 7255 & 4001 & 5890 & 6661 \\
\hline \multirow[t]{2}{*}{ Green peach aphids } & yes & 0 & 0 & 0 & 0 & 0 & 0 \\
\hline & no & 0 & 0 & 0 & 0 & 0 & 0 \\
\hline \multirow[t]{2}{*}{ Western flower thrips } & yes & 0 & 0 & 0 & 0 & 0 & 0 \\
\hline & no & 0 & 0 & 0 & 0 & 0 & 0 \\
\hline \multirow[t]{2}{*}{ Tomato leaf-minor flies } & yes & 0 & 0 & 0 & 0 & 0 & 0 \\
\hline & no & 285 & 583 & 255 & 401 & 589 & 361 \\
\hline
\end{tabular}

a Number of experiment

\section{Copyrights}

Copyright for this article is retained by the author(s), with first publication rights granted to the journal.

This is an open-access article distributed under the terms and conditions of the Creative Commons Attribution license (http://creativecommons.org/licenses/by/4.0/). 